\title{
Perspectives
}

\section{Molecular Genetics of Intestinal Glucose Transport}

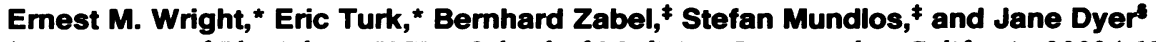 \\ *Department of Physiology, UCLA School of Medicine, Los Angeles, California 90024-1751; ' Department of Pediatrics, University of \\ Mainz, D-6500 Germany; and \$Department of Biochemistry, University of Wales, Dyfed SY23 3DD United Kingdom
}

\section{Introduction}

While it has been known for about a century that dietary sugars are actively absorbed from the small intestine, the mechanisms involved have been elucidated only over the past 30 years. In the case of dietary glucose and galactose, the energy-requiring step is at the brush border membrane of the enterocyte. The energy is provided by the sodium electrochemical potential gradient across the membrane, and the cotransport of $\mathrm{Na}^{+}$and glucose (galactose) across the brush border membrane results in the accumulation of sugar within the enterocyte. The absorption process is then completed by the diffusion of sugar out of the cell across the basolateral membrane into the blood. The $\mathrm{Na}^{+} /$glucose cotransporter has been identified as a 73-kD integral membrane protein, and the gene has been cloned and sequenced.

Clinical interest in the intestinal brush border $\mathrm{Na}^{+} /$glucose cotransporter has focused on diarrhea and malabsorption syndromes, e.g., glucose-galactose malabsorption. In the case of diarrhea induced by agents such as Vibrio cholerae and Escherichia coli, the most effective treatment is oral rehydration therapy (1) and this relies on the ability of glucose to activate intestinal salt (and water) absorption via the $\mathrm{Na}^{+}$/glucose cotransporter (Fig. 1). It is estimated that four million children under five die from diarrhea each year in the developing nations. Oral rehydration therapy, a simple, inexpensive treatment, now saves about a million small children annually.

In this article, the function, structure and molecular genetics of the intestinal $\mathrm{Na}^{+}$/glucose cotransporter will be summarized and then data will be presented to show that a single missense mutation in the gene is sufficient to cause life-threatening diarrhea.

\section{Background}

Research over the past 30 years has resulted in a fairly clear understanding of the mechanisms involved in the absorption of dietary carbohydrate from the small intestine. The digestion of food results in the liberation of free monosaccharides which are transported across the mature enterocytes lining the villi of the intestinal mucosa. Depending upon the diet, these monosaccharides are largely D-glucose, D-galactose, and D-fructose.

\footnotetext{
Address correspondence to Ernest M. Wright, Department of Physiology, UCLA School of Medicine, Los Angeles, CA 90024-1751.

Received for publication 08 May 1991 and in revised form 04 June 1991.
}

J. Clin. Invest.

(C) The American Society for Clinical Investigation, Inc.

$0021-9738 / 91 / 11 / 1435 / 06 \$ 2.00$

Volume 88, November 1991, 1435-1440
In the case of glucose and galactose, the transport systems are well understood, but little is known about fructose absorption. A simple model showing the mechanism of glucose and galactose absorption is illustrated in Fig. 1. D-Glucose and D-galactose, liberated from dietary carbohydrate by digestive enzymes, are first transported across the brush border membrane of the enterocyte by the $\mathrm{Na}^{+} /$glucose cotransporter. By coupling sugar transport to sodium transport the sodium concentration and electrical gradients are harnessed to energize the accumulation of the sugar within the enterocyte. This uphill transport of sugar is called secondary-active transport. Once the sugar is within the cell it passes out of the cell to the blood across the basolateral membrane via the facilitated glucose transporter. The intestinal facilitated transporter is a member of the gene family that includes the glucose transporters in erythrocytes, liver, and muscle and fat cells $(2,3)$. Two of these genes, GLUT2 and GLUT5, are expressed in the small intestine, but the relative importance of the two gene products is unknown. There is no structural or functional homology between the facilitated and $\mathrm{Na}^{+}$gene families.

\section{Kinetics}

The $\mathrm{Na}^{+}$/glucose cotransporter, first recognized by Crane and his colleagues in 1960 (4-6), now belongs to a major class of membrane proteins called cotransporters (or symporters). These exist in bacteria, plants, and animal membranes, and are responsible for the "active" accumulation of sugars, amino acids, carboxylic acids, and some ions (e.g., $\mathrm{Cl}, \mathrm{PO}_{4}, \mathrm{SO}_{4}, \mathrm{I}$ ) into cells. In bacteria and plants the driver ions are usually protons, while in animal cells they are usually sodium ions.

Much of the early work on the kinetics of the intestinal brush border $\mathrm{Na}^{+} /$glucose cotransporter was carried out in intact mucosa (4), whereas the more recent work has been on isolated cells (5) or brush border membrane vesicles (6-8). This work established that there is one major $\mathrm{Na}^{+}$/glucose cotransporter that handles all hexoses with an equatorial hydroxyl group on carbon-2. D-Glucose and D-galactose are the natural substrates, whereas sugars such as 3-O-methylglucoside and $\alpha$-methyl-D-glucopyranoside ( $\alpha \mathrm{MDG})^{1}$ are nonmetabolized substrates. It should be noted that $\alpha \mathrm{MDG}$ is not handled by the facilitated glucose transporter, and so this sugar can be used to functionally isolate the contributions of the $\mathrm{Na}^{+}$cotransporter. In the presence of saturating $\mathrm{Na}^{+}$concentrations the $K_{\mathrm{m}} \mathrm{s}$ for D-glucose and $\alpha \mathrm{MDG}$ in brush border vesicles are in the range of $0.1-1 \mathrm{mM}$. Phlorizin is a very specific competitive inhibitor of the $\mathrm{Na}^{+}$/glucose cotransporter with a $K_{\mathrm{i}}$ of 5-10 $\mu \mathrm{M}$. The D-glucose moiety of this inhibitor competes for

1. Abbreviation used in this paper: $\alpha \mathrm{MDG}, \alpha$-methyl-D-glucopyranoside. 


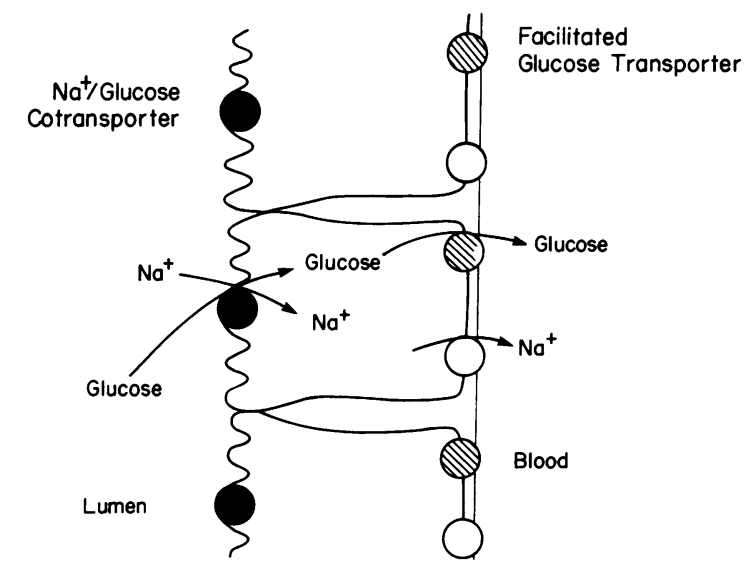

Figure 1. A simple model showing the two-stage transport of glucose (galactose) across the mature enterocytes of the small intestine. Sugar is absorbed in a two-stage process: the first is the uphill transport from lumen to cell across the brush border membrane by the cotransporter; and the second is the diffusion out of the cell across the basolateral membrane by the facilitated transporter. The cotransporter is energized by the $\mathrm{Na}^{+}$gradient (concentration and electrical) across the brush border, and this is maintained by the basolateral

$\mathrm{Na}^{+} / \mathrm{K}^{+}$-ATPase (pump). The addition of sugar to the lumen, therefore, increases net absorption of sodium and water across the intestine.

D-glucose at the active site for sugar binding, and the phloretin moiety enhances the binding affinity by at least an order of magnitude (Fig. 2). Phlorizin analogues are inactive when Dglucose is replaced by nontransported sugars, and the phloretin aglucon is a poor inhibitor. There is evidence that the $-\mathrm{OH}$ group of the hydroxyphenyl ring is specifically involved in phlorizin binding to the transporter.

$\mathrm{Na}^{+}$is specifically required to drive the uphill transport of sugars, but there are suggestions that $\mathrm{H}^{+}$and perhaps $\mathrm{Ln}^{+++}$ may mimic $\mathrm{Na}^{+}$, albeit in an inefficient manner. At saturating sugar concentrations, the $K_{\mathrm{m}}$ for $\mathrm{Na}^{+}$is in the range of $10-40$ $\mathrm{mM}$ and there is kinetic evidence that the $\mathrm{Na}^{+}$to sugar coupling coefficient is 2 . Although the kinetics of the $\mathrm{Na}^{+}$interaction with the cotransporter have been investigated by many workers, there is some controversy about the results. Whereas it is generally accepted that the major effect of $\mathrm{Na}^{+}$is to decrease the apparent sugar $K_{\mathrm{m}}$, e.g., from $>50 \mathrm{mM}$ in the absence of $\mathrm{Na}^{+}$to $<1 \mathrm{mM}$ in the presence of $150 \mathrm{mM} \mathrm{NaCl}$, there is no consistent effect of $\mathrm{Na}^{+}$on the $V_{\max }$. There is ample evidence to show that the cotransporter is electrogenic; i.e., sugars depolarize the membrane potential, and the rate of sugar transport is voltage dependent. As a result, perfusing the intestine with sugar changes the potential difference across the intestine wall by 5-10 $\mathrm{mV}$ and this has been used clinically to test for defects in sugar absorption.

\section{Identity of the $\mathrm{Na}^{+} /$glucose cotransporter}

Over the past decade increasing evidence has been obtained to identify the intestinal brush border cotransporter. Semenza's group provided the first tentative identification of $\mathrm{a} \sim 73 \mathrm{kD}$ protein using a photoaffinity analogue of the specific inhibitor phlorizin (7). This was confirmed (9) using covalent fluorescent probes and immunological techniques (monoclonal antibodies and polyclonal antipeptide antibodies). On the basis of radiation inactivation of $\mathrm{Na}^{+} /$glucose cotransport and immunoreactivity, it has been suggested (10) that the functional brush border transporter is a homotetramer (Fig. 3). Interestingly, the $\mathrm{Na}^{+}$-independent transport of D-glucose in brush borders was not sensitive to radiation, and supports the contention that the cotransporter is not responsible for this mode of glucose transport.

\section{Cloning}

Using a novel cloning technique, expression cloning, this UCLA laboratory (11) cloned, expressed, and sequenced the

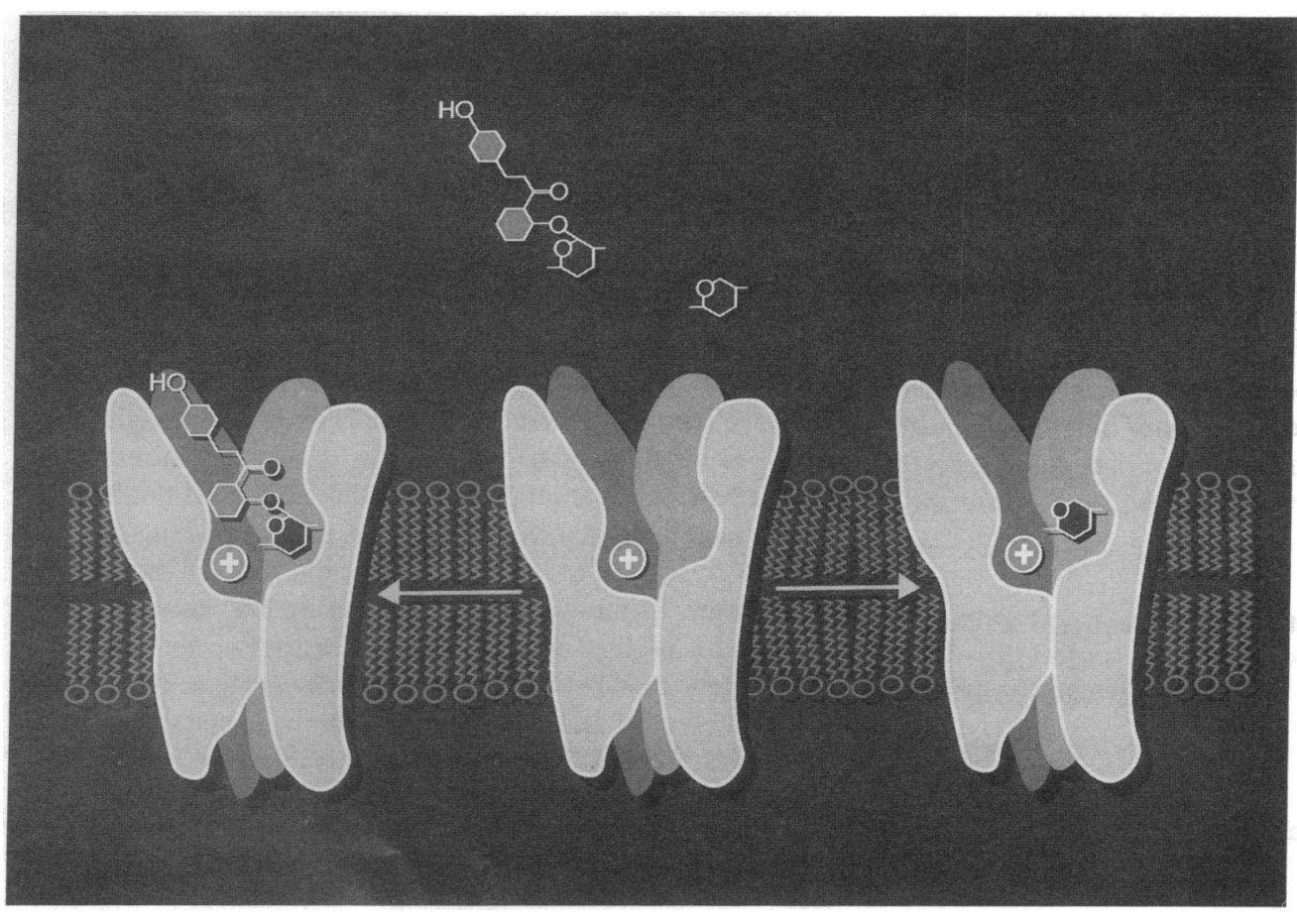

Figure 2. A model showing the competition between D-glucose and phlorizin for the sugar binding site on the brush border $\mathrm{Na}^{+} /$glucose cotransporter. The transporter is presented as a homotetramer in the $\mathrm{Na}^{+}(+)$conformation. Neither substrate nor inhibiter bind significantly in the absence of $\mathrm{Na}^{+}$. Phlorizin with a binding constant of $\sim 5 \mu \mathrm{M}$ has higher affinity for the active site than D-glucose with a binding constant $\sim 200 \mu \mathrm{M}$. The higher affinity of phlorizin is due to the phloretin moiety with the - OH group on the hydroxyphenyl ring. Phlorizin is not translocated across the membrane. 


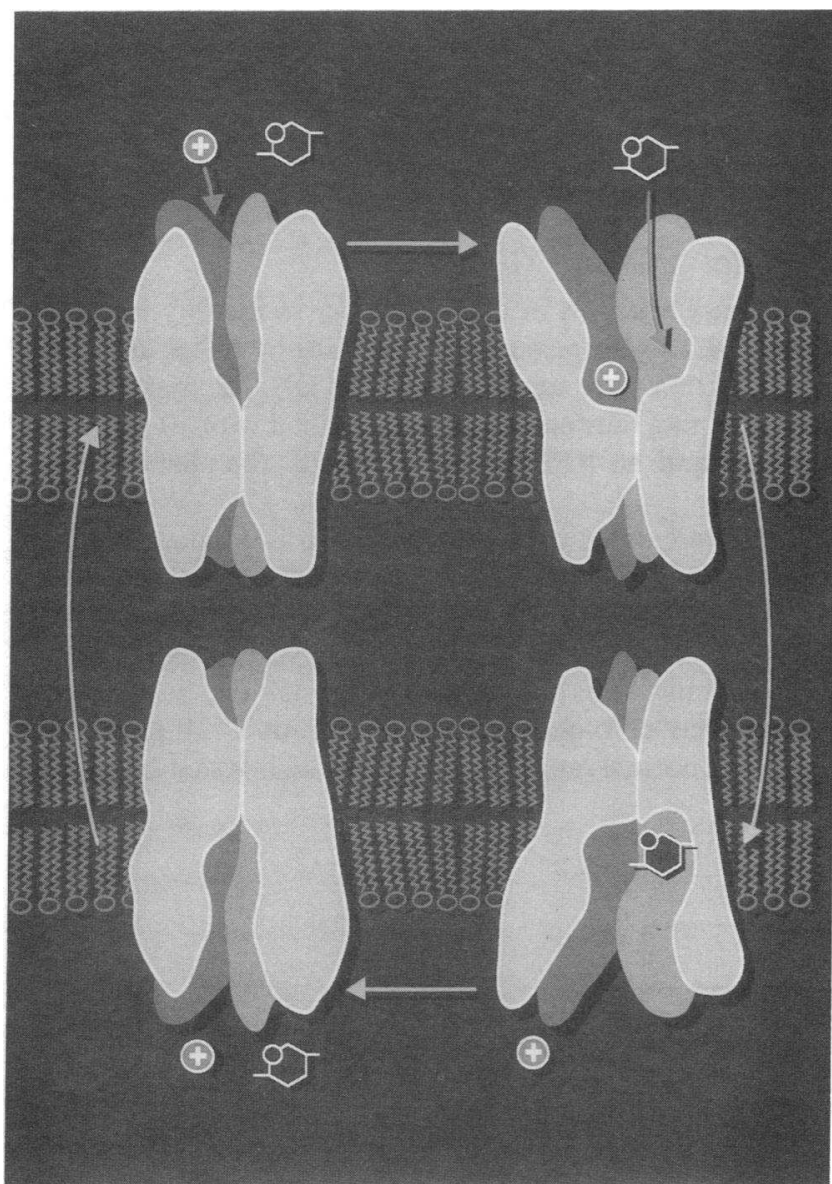

Figure 3. The brush border cotransporter is presented as a homotetramer of a $75-\mathrm{kD}$ integral membrane protein. In the absence of $\mathrm{Na}^{+}, \mathrm{D}$-glucose is unable to bind $\left(K_{\mathrm{m}} \gg 50 \mathrm{mM}\right)$, but in the presence of $\mathrm{Na}^{+}$, the ion $(\oplus)$ binds to produce a conformation change that now permits the sugar to bind $\left(K_{\mathrm{m}} \ll 1 \mathrm{mM}\right)$. For simplicity only, one of the two $\mathrm{Na}^{+}$binding sites is shown. The fully loaded cotransporter undergoes another conformation change to present the substrates to the internal face of the membrane where the $\mathrm{Na}^{+}$and sugar dissociate and the active sites are then returned to face the outside of the cell. Under physiological conditions the rate limiting steps are the membrane translocation steps and these exhibit high energies of activation. (Figure redrawn from reference 10 ). rabbit $\mathrm{Na}^{+}$/glucose cotransporter in 1987 , and subsequently cloned, sequenced, and expressed the human cotransporter two years later (12). The human cDNA codes for a protein of 664 residues. $86 \%$ of the residues are identical in the rabbit and human sequences and another $10 \%$ are conservative substitutions. Similar clones with $>84 \%$ identity have also been isolated from the rabbit and pig kidney (13). There is, however, no homology to the facilitated glucose transporters or to any other animal protein in the data bases.

A secondary structure model of the human intestinal $\mathrm{Na}^{+} /$ glucose cotransporter is shown in Fig. 4. In this model there are 12 transmembrane spanning domains with the amino and carboxyl terminals on the cytoplasmic face of the membrane (detailed hydrophobicity plots suggest between 11 and 13 transmembrane domains). The protein is glycosylated at one site $\left(A n^{248}\right)$, but glycosylation has little effect on the function of the protein (14).

The cotransporter has been functionally expressed in Xenopus oocytes and cultured insect (sf9) and mammalian (COS-7) cells $(15,16)$. Injection of cRNA into oocyte increases $\mathrm{Na}^{+}$-dependent sugar ( $\alpha$ MDG and glucose) uptake more than 1,000fold greater than in $\mathrm{H}_{2} \mathrm{O}$-injected cells. In each cell type the cloned transporter exhibits all the properties of the classical $\mathrm{Na}^{+} /$glucose cotransporter summarized above; i.e., sugar selectivity, $\mathrm{Na}^{+}$selectivity, sugar $K_{\mathrm{m}}$, and phlorizin $K_{\mathrm{i}}$ are all virtually identical. The highly efficient expression in oocytes has led to a direct study of the cotransporter current-voltage relations $(17,18)$. In cRNA-injected oocytes the cotransporter currents are in the range of 400-600 nA/oocyte, and the kinetic properties agree closely with the radioactive tracer studies; e.g. at physiological membrane potentials the $K_{\mathrm{m}}$ values for sugars and $\mathrm{Na}^{+}$, and the $K_{\mathrm{i}}$ for phlorizin are identical to those measured by tracer techniques. These electrical experiments also show that D-glucose, 3- $O$-methylglucoside, D-galactose, and $\alpha$ methyl-D-glucopyranoside are all transported by the cloned transporter, i.e., a single transporter handles all these hexoses. This is consistent with competition studies in brush border vesicles, intact cells, and tissues.

\section{The gene}

The chromosomal location of the human intestinal gene (SGLT1) was determined by Southern blot analysis of genomic DNA from mouse-human somatic cell hybrids (19). The gene

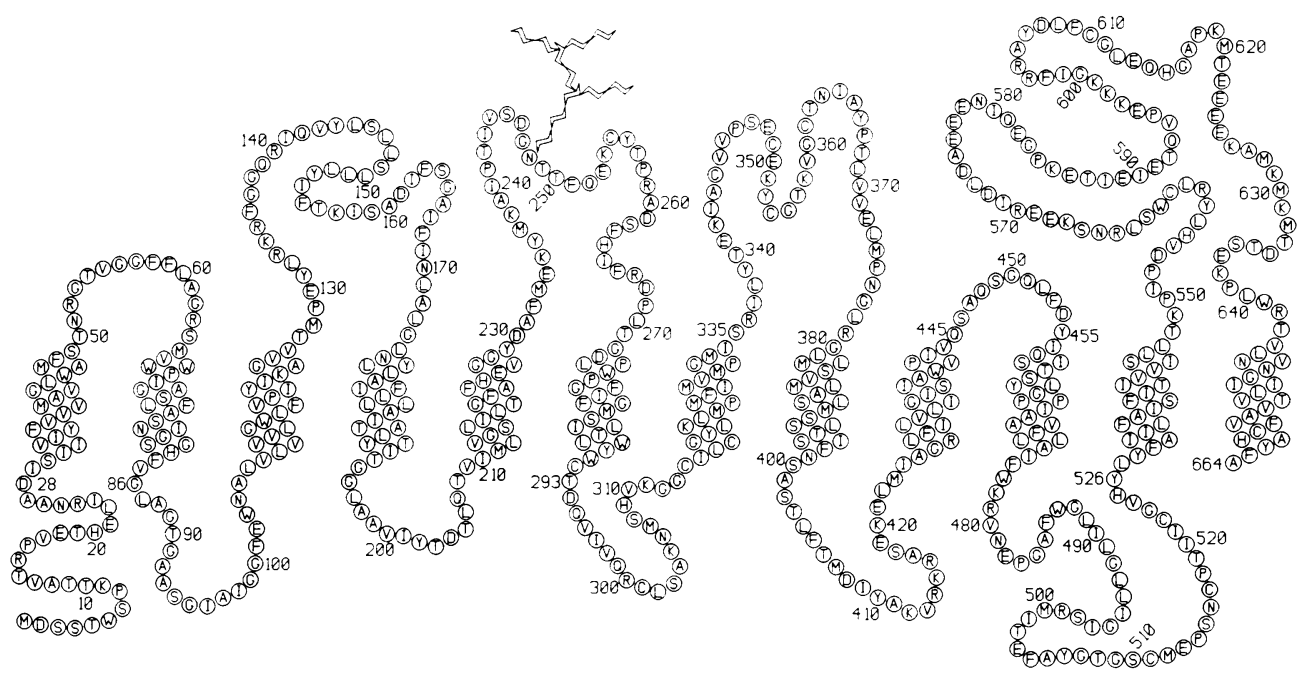

Figure 4. The primary amino acid sequence of the human $\mathrm{Na}^{+} /$glucose cotransporter arranged in a secondary structure model. The amino terminal is in the cytoplasm and there are 12 membrane-spanning domains shown in a helical conformation. There is one $N$-linked glycosylation site at $\mathrm{Asn}_{248}$ which adds $\sim 12 \mathrm{kD}$ to the relative molecular weight on SDS-PAGE. 
resides on chromosome 22 and further analysis of hamster-human hybrids, selectively retaining portions of this chromosome, allowed specific assignment of the gene to the q11.2 $\rightarrow$ qter region. Preliminary attempts to map the gene have indicated that it is much larger than $80 \mathrm{~kb}$. Work is currently in progress to map the exons, introns, and promoter regions of the gene.

\section{Glucose-galactose malabsorption}

This disease, first identified almost 30 years ago, is characterized by a neonatal onset of severe, watery diarrhea that results in death unless glucose and galactose are removed from the diet $(9,20)$. An immediate improvement is seen when the patients are placed on an artificial milk free of glucose, galactose, and lactose. Laboratory studies of biopsy samples from patients free of diarrhea show normal histology, normal disaccharidase activities, and normal amino acid transport. However, the mucosal biopsies are not able to accumulate glucose or galactose, suggesting a defect in the brush border $\mathrm{Na}^{+} /$glucose cotransporter. This has been confirmed in brush border vesicle experiments.
The children affected by GGM are of diverse origin: the disease has been reported in Europe, North America, Japan, Iraq, Morocco, Syria, and Bangladesh. An extensive pedigree study of six cases in Sweden (21) revealed that transmission of the disease involved consanguineous mating, indicating an autosomal recessive mode of inheritance.

\section{Molecular genetics of GGM}

Preliminary attempts in this laboratory to identify mutations in the SGLT1 gene responsible for GGM by RFLP analysis of genomic DNA were unsuccessful. The DNA from three families containing four patients was examined with 10 restriction enzymes, and no RFLP segregating with the phenotype was found.

In a more direct approach, mRNA was isolated for cDNA production from intestinal biopsies taken from two sisters diagnosed with GGM (22). The girls presented with severe diarrhea within the first days of life. The diagnosis was based on oral sugar tolerance tests and these are shown in Fig. 5. The fasting serum levels of D-glucose, D-galactose, and D-fructose were within the normal range. When each child ingested $2 \mathrm{~g} / \mathrm{kg}$ body

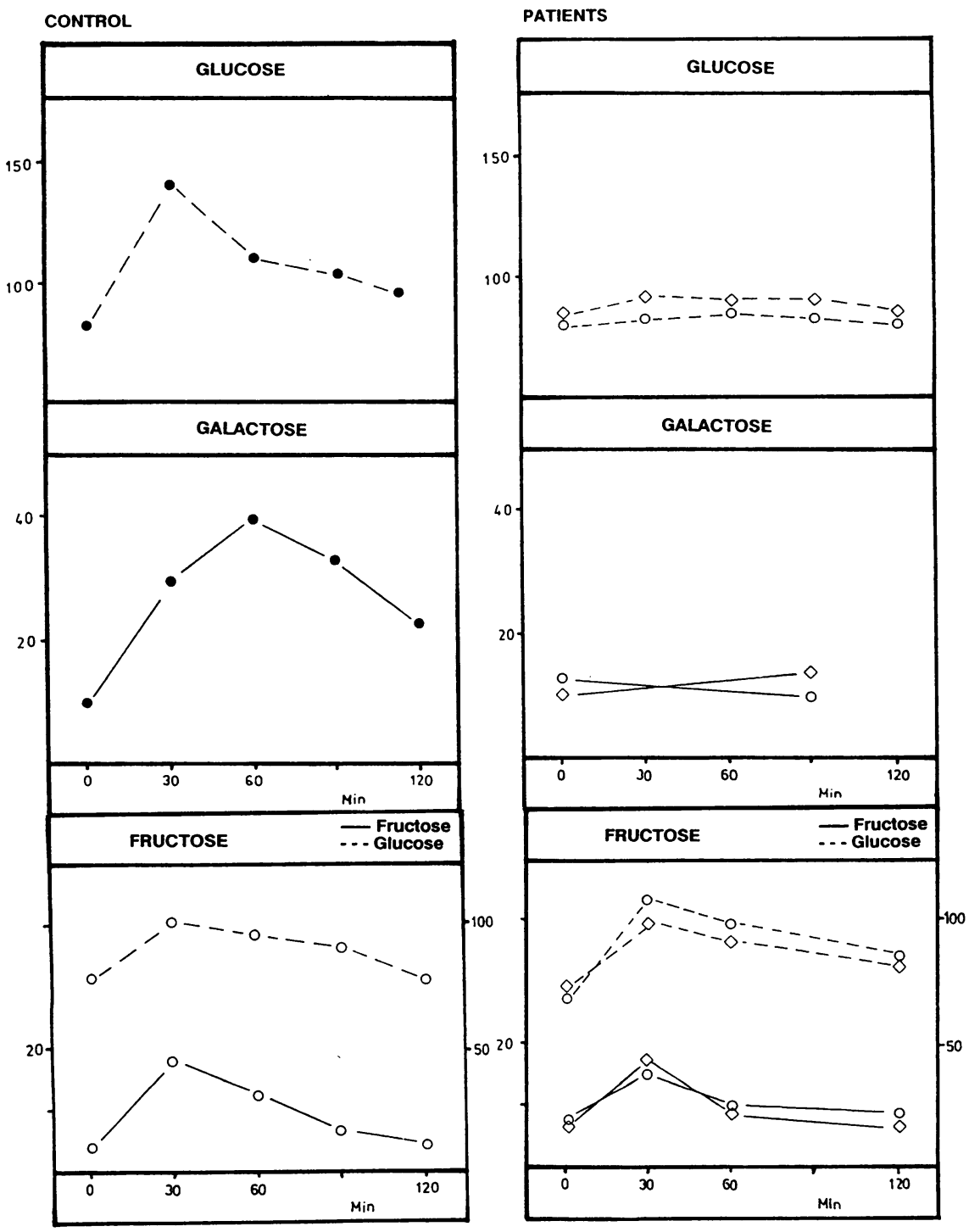

Figure 5. Oral sugar tolerance tests on two patients with glucose-galactose malabsorption $(\infty)$ and on a control subject. On each test the subject was fasted overnight and then given $2 \mathrm{~g} / \mathrm{kg}$ body weight of D-glucose, D-galactose, or D-fructose. Plasma sugar levels (mg\%) were recorded before ingestion of the sugar, and for $2 \mathrm{~h}$ thereafter. Note the rapid rise in glucose and galactose plasma levels in the control which is in direct contrast to that observed with the two glucose-galactose patients. The fructose tolerance test was normal in the patients. 
weight of either D-glucose or D-galactose the serum levels remained flat for at least $2 \mathrm{~h}$, whereas in the control plasma, D-glucose and D-galactose increased rapidly within $1 \mathrm{~h}$ as expected. In the patients and in the control subject, there was no difference in oral D-fructose tolerance test results. The serum glucose and fructose levels increased and peaked at $30 \mathrm{~min}$ and returned to normal levels within $2 \mathrm{~h}$. These tests showed that in both patients, D-glucose and D-galactose absorption were severely impaired, whereas D-fructose absorption was within normal limits. D-Xylose absorption was also normal. There was no renal glycosuria and each patient had a normal duodenal biopsy. It was concluded that each child suffered from glucose-galactose malabsorption and they were, subsequently, successfully maintained on a glucose/galactose-free diet.

To elucidate the molecular defect underlying the disease, cDNA coding for the brush border $\mathrm{Na}^{+}$/glucose cotransporter was produced from the duodenal biopsy samples. RNA was first isolated, and cDNA was then synthesized by reverse transcriptase. Overlapping segments of cDNA coding for the cotransporter were amplified using the polymerase chain reaction (PCR) and oligonucleotide primers, based on the normal human sequence. The entire cDNA coding region of one child was sequenced (Fig. $6 \mathrm{~A}$ ) and a single base change was discovered at position 92 (guanine to adenine). This $\mathrm{G} \rightarrow \mathrm{A}$ base change was also found in the other afflicted sister. The absence of a $\mathrm{G}$ signal at position 92 indicated that the mutation occurred on each chromosome. We also examined the genomic DNA of each parent for this mutation. The exon containing the coding sequence was amplified by PCR and sequenced, revealing both an $A$ and $a \mathrm{G}$ at position 92 . This established that one chromosome in each parent carried a mutation at position 92 . Because the base change destroys a restriction site for Eco RV, this allowed independent confirmation of the mutation by Southern blot analysis. Eco RV digests of genomic DNA from the four GGM family members and 20 controls were probed with a $5^{\prime}$ terminal SGLT1 cDNA fragment. All 20 controls showed a 4.1-kb band which was absent in the two sisters. The parents' DNA, on the other hand, showed a weak 4.1-kb band. This analysis allowed us to confirm that the position $92 \mathrm{G} \rightarrow \mathrm{A}$ mutation was not a PCR amplification error. The mutation results in a change in amino acid 28 from an aspartate to asparagine (Fig. $6 \mathrm{~B}$ ).

Molecular genetic studies have been extended to four other patients with this autosomal recessive disease. Exon 1 of the gene has been amplified by PCR in each patient and none had the $\mathrm{Asp}_{28} \rightarrow \mathrm{Asn}_{28}$ mutation. In these four patients the defect must be at some other locus in the gene. In three different patients, Western blot analysis has shown that the cotransport protein is present in the brush border membrane (Hirayama, Shirazi-Beechey, Walker-Smith, and E. M. Wright, unpublished observation), and this indicates that in these three cases the defect is also likely to be a missense mutation.

To establish the functional consequences of this $\mathrm{Asp}_{28} \rightarrow$ $\mathrm{Asn}_{28}$ mutation, the activity of the transporter expressed in Xenopus oocytes was measured. The wild-type SGLT 1 clone was converted by cassette mutagenesis to a new clone bearing the $G \rightarrow$ A mutation. cRNA was then transcribed from the wild-type and mutant clones and injected into oocytes. The oocytes were then assayed for $\alpha \mathrm{MDG}$ uptake $4 \mathrm{~d}$ later. The wild-type RNA stimulated $\alpha$ MDG uptake 32-fold, whereas the

A

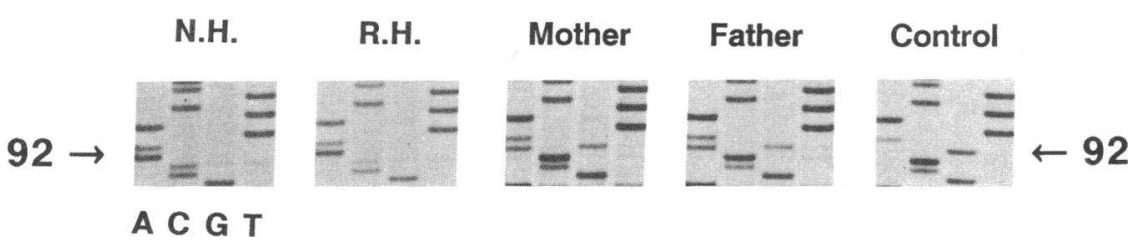

B

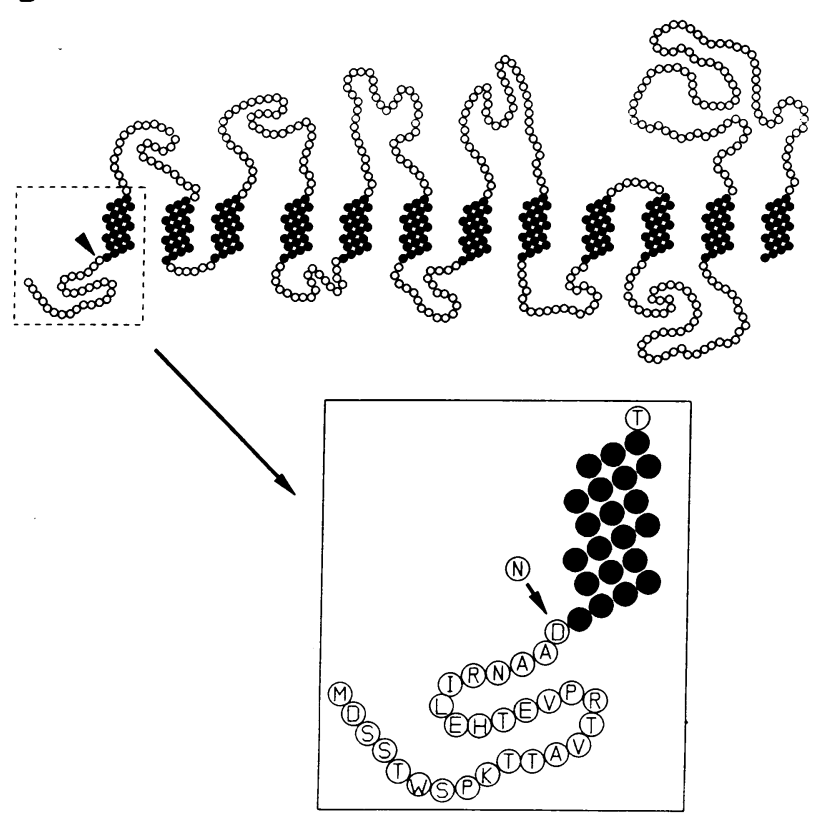

Figure 6. The mutation in the $\mathrm{Na}^{+} /$glucose cotransporter gene responsible for glucose-galactose malabsorption in the two sisters shown in Figure 5: $(A)$ Shows the region of the sequencing gel in the two sisters, the parents and a control subject. Note the $G \rightarrow$ A base change at position 92 in N.H. and R.H., and the presence of $G$ and $A$ at position 92 in both parents. $(B)$ The $\mathrm{G} \rightarrow \mathrm{A}$ base change results in the replacement of an aspartic acid residue with an asparagine at position 28. As shown on the secondary structure model, this occurs at the interface between the cytoplasm amino terminal and the first transmembrane segment of the protein. (Taken from reference 22 ). 
mutant RNA failed to elicit any uptake above background. Therefore, it was concluded that the Asp $\rightarrow$ Asn mutation causes the defect in intestinal glucose and galactose absorption in the two sisters. These results firmly establish that the SGLT1 gene codes for the protein responsible for normal intestinal glucose absorption. There has been some debate in the literature about the presence of multiple $\mathrm{Na}^{+}$-dependent glucose transporters in the intestinal brush border, but our results clearly indicate that if additional carriers exist in the children, they are of minor importance. Finally, it is clear that a single mutation in the gene is sufficient to cause a severe, chronic diarrhea. Although the diarrhea is controlled by removing lactose, glucose, and galactose from the diet, it returns, even in adult patients, with ingestion of carbohydrates.

Future work on this transporter will proceed in at least three areas. One is to examine other GGM patients to $(a)$ determine the frequency of the $\mathrm{Asp}_{28} \rightarrow \mathrm{Asn}_{28}$ mutation, and $(b)$ identify other mutations in the gene responsible for the disease. A second is to examine the structure of the cotransporter using molecular, biochemical, and physiological techniques to identify amino acid residues involved in $\mathrm{Na}^{+}$, D-glucose, and phlorizin binding sites, and to deduce the mechanism of $\mathrm{Na}^{+} / \mathrm{glu}$ cose cotransport. A third is to study the factors involved in regulation of expression of this gene in the GI tract and other organs.

Finally, although this is the first mammalian $\mathrm{Na}^{+}$cotransporter to be cloned, it is anticipated that others will be cloned in the near future. This will lead to an explosion of information about the physiology and pathophysiology of intestinal nutrient absorption.

\section{Acknowledgments}

This work is supported in part by grants from the National Institutes of Health (DK19567 \& DK36700).

\section{References}

1. Hirschhorn, N., and W. B. Greenough. 1991. Progress in oral rehydration therapy. Sci. Am. 264(No. 5):50-56.

2. Gould, G. W., and G. I. Bell. 1990. Facilitative glucose transporters: an expanding family. Trends Biochem. Sci. 15:18-23.

3. Carruthers, A. 1990. Facilitated diffusion of glucose. Physiol. Rev. 70:1135-1176.

4. Schultz, S. G., and P. F. Curran. 1970. Coupled transport of sodium and organic solutes. Physiol. Rev. 50:637-718.
5. Kimmich, G. A. 1981. Intestinal absorption of sugar. In Physiology of the Gastrointestinal Tract. Volume 2. L. R. Johnson, J. Christensen, M. I. Grossman, E. D. Jacoson, and S. G. Schultz, editors. Raven Press, New York. 1035-1061.

6. Hopfer, U. 1987. Membrane transport mechanisms for hexoses and amino acids in the small intestine. In Physiology of the Gastrointestinal Tract. Volume 2. 2nd ed. L. R. Johnson, J. Christensen, M. J. Jackson, E. D. Jacobson, J. H. Walsh, editors. Raven Press, New York. 1499-1526.

7. Semenza, G., M. Kessler, M. Hosang, and U. Schmidt. 1984. Biochemistry of the $\mathrm{Na}^{+}$, D-glucose cotransporter of the small intestinal brush-border membrane. Biochim. Biophys. Acta. 779:343-379.

8. Schultz, S. G. 1986. Ion-coupled transport of organic solutes across biological membranes. In Physiology of Membrane Disorders. T. Andreoli, J. Hoffman, D. Fanestil, and S. Schultz, editors. Plenum Publishing Corp., New York. 283294.

9. Wright, E. M. 1990. Intestinal sugar transport. In Textbook of Secretory Diarrhea. E. Lebenthal and M. Duffey, editors. Raven Press, New York. 119124.

10. Stevens, B. R., A. Fernandez, B. Hirayama, E. Wright, and E. Kempner. 1990. Intestinal brush border membrane $\mathrm{Na}^{+}$/glucose cotransporter functions in situ as a homotetramer. Proc. Natl. Acad. Sci. USA. 87:1456-1460.

11. Hediger, M. A., M. Coady, T. Ikeda, and E. Wright. 1987. Expression cloning and cDNA sequencing of the $\mathrm{Na}^{+}$/glucose cotransporter. Nature (Lond.). 330:379-381.

12. Hediger, M. A., E. Turk, and E. Wright. 1989. Homology of the human intestinal $\mathrm{Na}^{+} /$glucose and $E$. coli $\mathrm{Na}^{+} /$proline cotransporters. Proc. Natl. Acad. Sci. USA. 86:5748-5752.

13. Coady, M. J., A. Pajor, and E. Wright. 1990. Sequence homologies among intestinal and renal $\mathrm{Na}^{+} /$glucose cotransporters. Am. J. Physiol. 259(Cell Physiol. 28):C605-C610.

14. Hediger, M., J. Mendlein, H.-S. Lee, and E. Wright. 1991. Biosynthesis of the cloned $\mathrm{Na}^{+} /$glucose. Biochim. Biophys. Acta. In press.

15. Ikeda, T. S., E.-S. Hwang, M. Coady, B. Hirayama, M. Hediger, and E. Wright. 1989. Characterization of a Na${ }^{+} /$glucose cotransporter cloned from rabbit small intestine. J. Membr. Biol. 110:87-95.

16. Birnir, B., H.-S. Lee, M. Hediger, and E. Wright. 1990. Expression and characterization of the intestinal $\mathrm{Na}^{+} /$glucose cotransporter in COS-7 cells. Biochim. Biophys. Acta. 1048:100-104.

17. Umbach, J. A., M. Coady, and E. Wright. 1990. The intestinal $\mathrm{Na}^{+} / \mathrm{glu}-$ cose cotransporter expressed in Xenopus oocytes is electrogenic. Biophys. J. 57:1217-1224.

18. Birnir, B., D. Loo, and E. Wright. 1991. Voltage clamp studies of the $\mathrm{Na}^{+}$/glucose cotransporter cloned from rabbit small intestine. Pfluegers Arch. Eur. J. Physiol. 418:70-85.

19. Hediger, M. A., M. Budarf, B. Emanuel, T. Mohandas, and E. Wright. 1989. Assignment of the human intestinal $\mathrm{Na}^{+}$/glucose cotransporter gene SGLT1) to the q11.2 $\rightarrow$ qter region of chromosome 22. Genomics. 4:297-300.

20. Desjeux, J.-F. 1989. Congenital selective $\mathrm{Na}^{+}$D-Glucose cotransport defects leading to renal glycosuria and congenital selective intestinal malabsorption of glucose and galactose. In The Metabolic Basis of Inherited Disease. C. Scriver, A. Beaudet, W. Sly, D. Valle, editors. McGraw-Hill Book Co., New York. 24632478.

21. Melin, K., and G. Meeuwisse. 1969. Glucose-galactose malabsorption. Acta Paediatr. Scand. Suppl. 188:19-24.

22. Turk, E., B. Zabel, S. Mundlos, J. Dyer, and E. Wright. 1991. Glucose/galactose malabsorption: a defect in the $\mathrm{Na}^{+}$/glucose cotransporter. Nature (Lond.). 350:354-356. 